Original Research Paper

\title{
The Role of Public Participation in Promoting Urban Planning
}

\author{
${ }^{1}$ Kaveh Ostad-Ali-Askari, ${ }^{2}$ Hossein Gholami, ${ }^{3}$ Shahide Dehghan and ${ }^{4}$ Mohsen Ghane \\ ${ }^{1 *}$ Department of Water Engineering, College of Agriculture, Isfahan University of Technology, Isfahan 8415683111, Iran \\ ${ }^{2}$ Department of Civil Engineering, Isfahan (Khorasgan) Branch, Islamic Azad University, Isfahan, Iran \\ ${ }^{3}$ Department of Geography, Najafabad Branch, Islamic Azad University, Najafabad, Iran \\ ${ }^{4}$ Department of Civil Engineering, South Tehran Branch, Islamic Azad University, Tehran, Iran
}

\author{
Article history \\ Received: 01-06-2018 \\ Revised: 02-08-2018 \\ Accepted: 27-08-2018 \\ Corresponding Author: \\ Kaveh Ostad-Ali-Askari \\ Department of Water \\ Engineering, College of \\ Agriculture, Isfahan University \\ of Technology, Isfahan \\ 8415683111 , Iran \\ Email: ostadaliaskari.k@of.iut.ac.ir \\ kaveh.oaa2000@gmail.com
}

\begin{abstract}
Each city has important and essential needs, which due to the development of modern cities, these needs occur despite to urban planning science. Future generation expectation of resources should also be consideredand urban planning should be defined and established based on participatory urbanization and citizen participation. The presence of citizens in decision-making and expressing their desire and needs in accordance with the current conditions of the community occurs in participatory urbanization. Participation has found a special place in urban planning theories. In today's world, people participation goes on like political, social, economic and so on. Planners make better use of popular forces to achieve a better society. This article tries to recall the planning process and the position of plannersand also uses a descriptive and comparative method to express the important theories of participatory urban development, such as the theory of Sherry Arnstein and Scott Davidson.
\end{abstract}

Keywords: Participatory Urbanization, Citizen Participate, Urban Planning

\section{Introduction}

Multinational tries to maintain the natural circumference are principally concerned with extensive, bio-different and relatively untouched ecosystems or with individual animal or vegetal species, either imperilled or menaced with extinction. Much less notice is being paid to that kind of in the natural world approximately where human beings live and work, to small-scale green regions in cities and to their profits to people. Enhancing experiential witness, however, demonstrates that the tendency of natural regions donates to the standard of living in many methods. Alongside many environmental and ecological services, urban nature prepares significant public and emotional profits to human societies, which improve human life with the significances and feelings. The topics considered concern people's incentives for civic nature, the psychological aspect connected with the experiment of nature and its significance for people's public welfare. Consequences affirm that the experiment of nature in urban circumferences source of affirmative senses and useful services, which perfect main non-material and non-consumptive person demands. Suggestions for the sustainability of the town will be surveyed and considered. Planning is a thinking process whose purpose (mainly) is to improve the welfare of the community (Forester, 2013). Planning should be considered as an activity that is influenced by the power of the citizen's presence in decision-making and their proximity and coordination with authorities and professionals, in order to meet their needs and desires in accordance with their living conditions and social and economic characteristics through Participatory and popular urban planning process as soon as possible. Despite a lot of studies on the position of planning in the country, few studies have done about the role of planners in the planning process, along with planning studies, perhaps few writings about the status of planners could be found. One can mention the study of Nasser Baraty about the challenges facing Iran's urban environment. The Skeffington Commission in the United Kingdom defined the participation of citizens as "participation in our opinion is to involve people in the formulation of policies and proposals. 
Providing information from authorities and the possibility of commenting on that information is an important part of the participation process, full participation only comes about where people can play an active role in the process of preparing the plan (Justin Hui, 1998). Citizen Participation in Urban and Urban Affairs first in the late 1950s and early 1960s was formed in America. During this period, several laws were passed based on citizen participation that changed the nature of urban decision-making processes. The concept of participation was introduced in England in the mid-1960s, after which other democracies welcomed it.

\section{The Process of Changing the Position of Planners}

The first planners were engineers, because, in the absence of urban planning, these were expensive city architects and civil engineers who came into action and for that very reason, as well as "the lack of an endogenous theory in the planning", The (scientific and technical) topics which were the predominant view of the engineers, opened their way to urban planning issues In this discussion, "Planning insists on being beyond morality and is often based on the logic of mathematics and engineering. In this type of planning, the bureaucratic system and the hierarchy are dominantand urban planning is limited to physical planning based on the distribution of land based on the desired standards and objectives.

By expanding social awareness and increasing the participation of people in the community, expectations for participation in the political power structure increased, Thus, the political participation of the people, along with the reign of local democracy, triggered the pressure and, eventually, changed the approaches to planning and reject the idea of comprehensiveness (especially comprehensive plans) (Suebvises, 2018). This thought was under the pressure of serious criticism as follows:

1. First, comprehensive planning requires a level of understanding, analysisand coordination of an organization that, if not impossible, is complex. This critique led to step by step planning

2. Second, the assumption of comprehensive planning was the existence of a common public interest, but the result was to ignore the needs of the poor, to defend one's benefit. This critique led to the call for supportive planning Third, the weakness of social participation in the various stages of traditional planning caused increased attention to participatory planning

\section{The Proposition of Planner}

Many of the planners interviewed are faced (in complete compliance with the results of the work of Vasu) with the problem of cognitive dissonance. They are caught up in their awareness of the political reality of their plurality and beliefs that must be addressed in a comprehensive and rational planning process away from the political process, for example "between two political or scientific options: Often chose Scientific City, or Cautiously chose both (Deitz et al., 2018).

They emphasized normative planning rather than positive planning in a completely inappropriate choice. For them, popular legitimacy was more important than government approval." (A summary of the results of all interviews) While in the programs they do, they give their employer's (the government) satisfaction their first priority; as suggested by Inza, the planning theory does not offer much of the content and logic of these combined positions but sees it as logically and psychologically untenable Perhaps, it can be said that these results, with a transitional stage, are related to the change in the planning paradigm in the countryand these responses are the first indications of planners' doubts over the dominant traditional planning paradigm in the country. However, traditional planning is prevalent in the countryand planning is about to changeand it should move away from the modernist planning and move towards community-based planning. In this type of planning, the public sphere, which is a political arena, is of great importance (Kovács et al., 2017).

\section{Participatory Planning}

Participatory planning is defined as follows:

"It is a set of processes which through them different groups and desires interact with each other, in order to agree on a program and its modalities." (Kim, 2017)

Participatory planning is based on the following principles:

1. The society is multiplied

2. In the community, there are legitimate contradictions between the interests of individuals

3. Individual or group strengths should not impose their views on others

4. The parties involved must interact with one another to complete each other's information and try to understand each other's perspective and reduce the controversy

5. No individual or group should be abandoned in the process of reaching an agreement Participatory planning should be done on the basis of specific actions 
6. New training is needed for development assistance personnel in participatory planning

7. Developing a participatory approach

8. Insurance of ratification of the government's participatory approach

9. Identify active agents in different tasks, their roles and the degree of their participation in these activities

10. Determine the active and passive participation required

11. Group Decision-making Development Method

12. Create local knowledge
13. The establishment of appropriate standards that have been developed in the community and modified by its reign

\section{Various Forms of People's Participation}

In Driskell view, there are several forms of participation that take place in two broad categories of participation and non-participation. Driskell in the Fig. 1 shows the types of participation in a two-dimensional form and in terms of the extent to which decisions are made (Justin Hui, 1998).

The dimensions of young people's participation

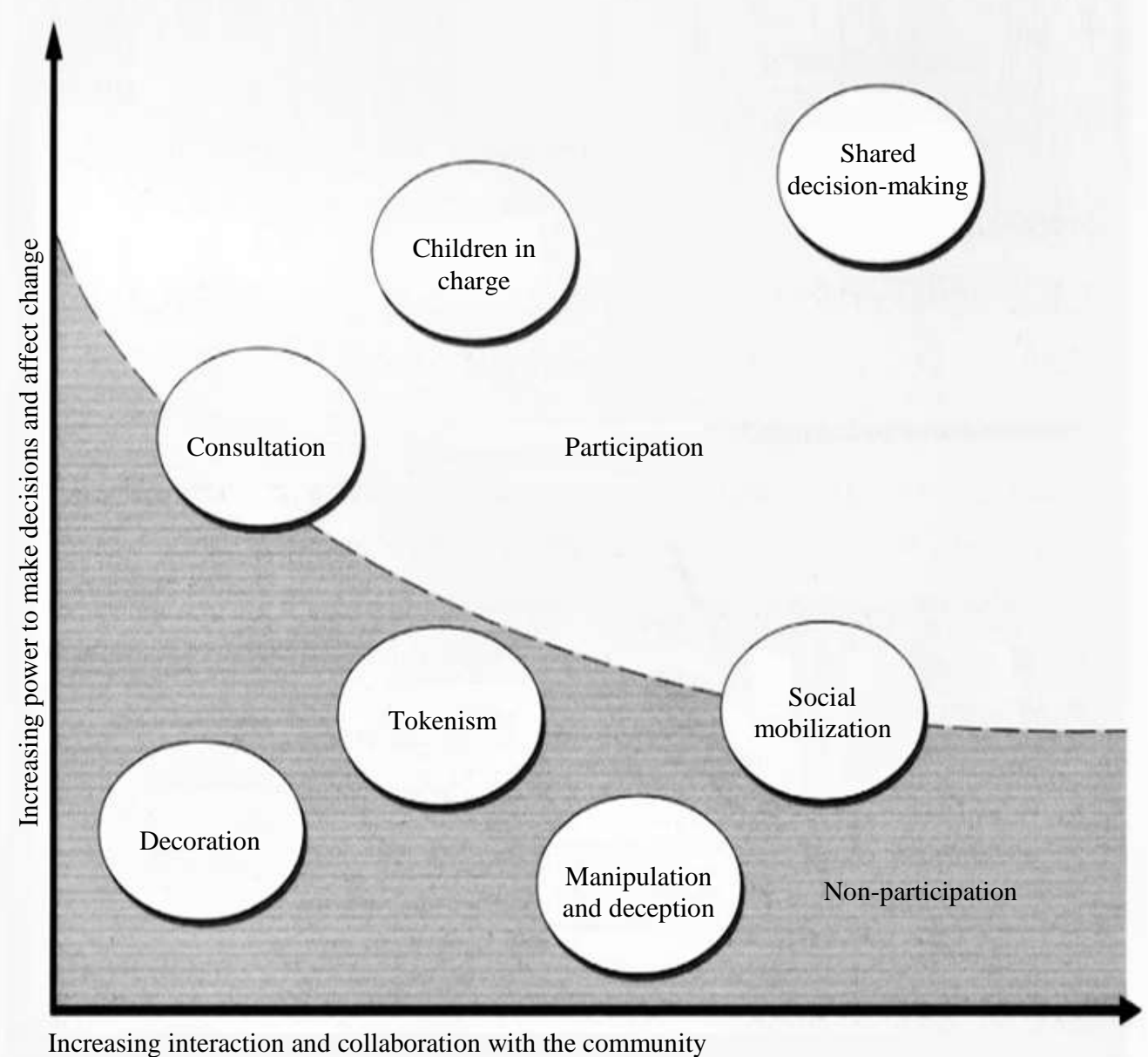

Fig. 1: Forms of participation and non-participation in the viewpoint of Driskell (Kim, 2017)

\section{Participatory Urban Planning Theories}

Several theories have been presented on participatory planning and participatory urban planning since the second half of the 1960s (Kim, 2017). Expression of all the above theories is beyond the scope of this article, henceforth, the five main theories are described here. The criterion for choosing these theories is the level of 
innovation and creativity, the theoretical strengthand the impact on subsequent theories.

\section{James Midgley (1986)}

Based on the response of governments to participation, Midgley divides it into four types.

\section{Anti-Participatory Mode}

Proponents of this idea believe in suppressing mass participation. Governments do not allow interference and public participation in policy formulation that may conflict with their overall social and economic objectives (Davidoff, 2012).

\section{Manipulated Mode of Participation}

In this mode, the government supports the participation of local communities with covert motives. In this approach, Local community participation is used to control social politics, with the knowledge that participation facilitates the implementation of the plan (Davidoff, 2012).

Overall, governments, with use of the Manipulated mode of participation pursue the following objectives:

1. Use of a participation to implement development projects

2. Control of Local Movements and Communities

3. Use of the attraction of participation to gain political-social legitimacy

\section{Incremental Mode of Participation}

In this mode, the government works in a two-way approach to deal with participation, it means that supports it in official positions but does not effectively work towards the implementation of participatory proposals (Davidoff, 2012).

\section{Genuine Mode of Participatio}

In this mode, the government fully supports social participation and works through the creation of mechanisms for the effective entry of local communities in all fields. In this participation mode, the government, in addition to establishing genuine local institutions, is committed to participatory activities through the training and strengthening of local communities, provision of materials and other forms of assistanceand also the coordination of decision making at central, regional, local levels (Davidoff, 2012).

\section{Sherry Arnstein (1996)}

In the late $1960 \mathrm{~s}$, the role of citizen participation in societies was noticed more and more. In an article published for the first time in 1969, Arnstein described and explained the concept of participation in a clear way (Rall et al., 2018). This article was later repeatedly used by other scholars and became the basis for proposing theories of participation. Arnstein used the citizen participation in terms of citizenship power and, to explain it, used the metaphor of the ladder of participation.

The Arnstein Ladder of citizen participation has the following steps (Fig. 2).

In the lowest level of the Arnstein ladder, there is no power for the citizens, in another word, the lack of participation in two categories shows itself that he calls them manipulation and therapy. In the Arnstein point of view, this manipulation implies that some government agencies have provided a mock figure of participation that their actual goal is to educate citizens in accepting the work that has already been clarified (Bice, 2018).

In the next step, another form of non-participation is introduced, called therapy. This kind of non-participation is both non-honest and selfish. Here, the goal is to find a way to reject the views and behaviours that the related organization does not agree with itself, but it cannot make this clear, so, under the coverage of citizen survey, rejects that view (Bice, 2018).

Other steps of the ladder are, informing and consultation. This step means informing citizens of the facts about the government's plans and their rights and responsibilities and the available solutions. Informing, consultation and citizen survey can be useful if it is real and the information flow is not one-sided (Bice, 2018).

\section{Scott Davidson (1998)}

In 1998, Scott Davidson designed the wheel of participation for citizen participation. It provides a variety of levels of participation without giving preference to one. In this model, decisions are made on a continuous interaction between government and citizens (Bice, 2018) (Table 1).

Table 1: Ladder of citizen participation (Kolonin, 2018)

\begin{tabular}{|c|c|c|c|c|c|c|c|}
\hline Non-participa & & Tokenism & & & Citizen power & & \\
\hline Manipulation & Therapy & Informing & Consultation & Placation & Participation & Delegated power & Citizen control \\
\hline
\end{tabular}




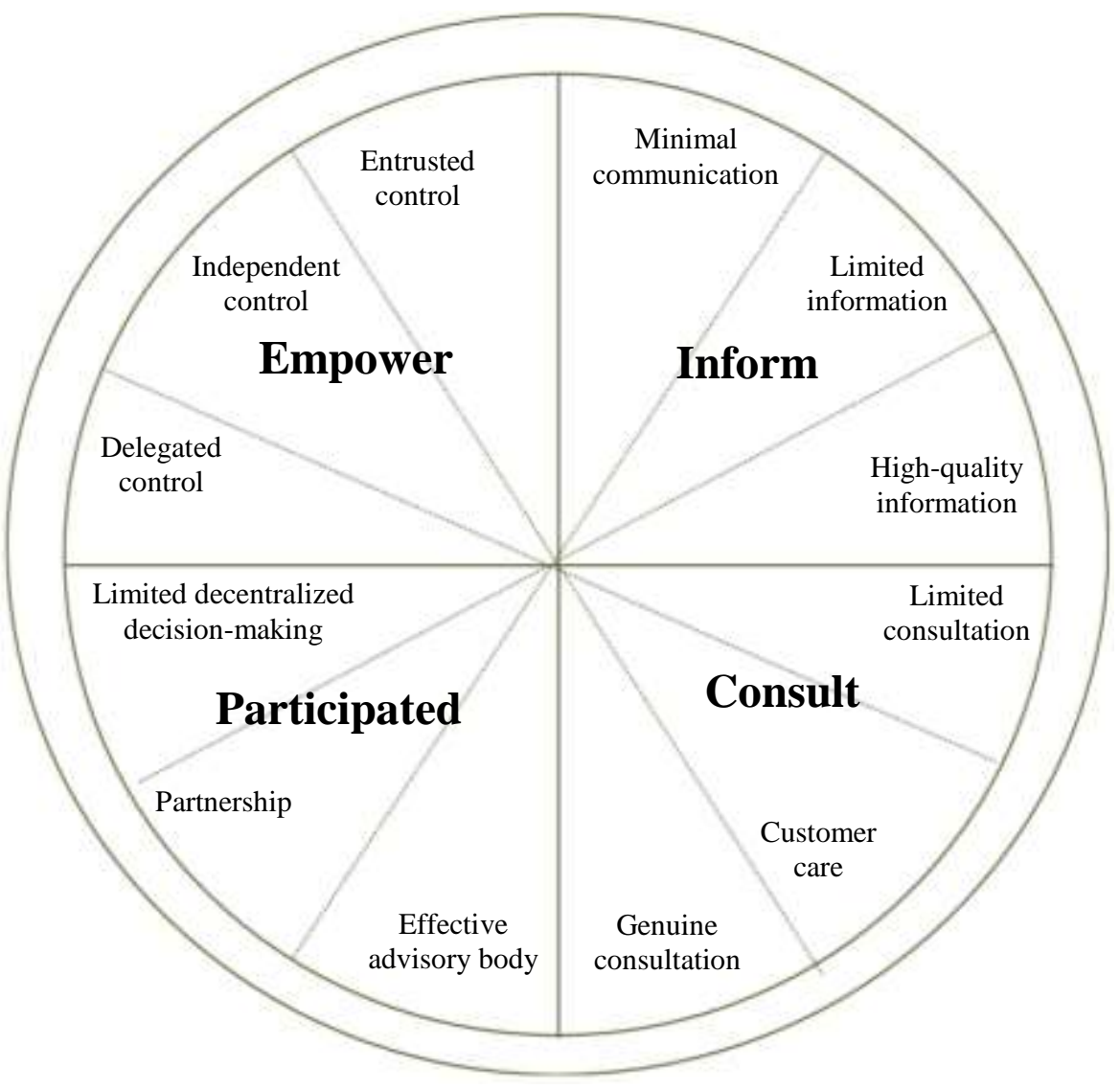

Fig.2: Wheel of participation, Davidson

Although Davidson does not take precedence or precedent for the levels involved in the participation, he essentially uses the wheel instead of the ladder, but it nevertheless has four levels of participation, which includes:
1) Inform
2) Consult
3) Participate
4) Empower

Participatory planning is based on the following principles:

1. The society is multiplied

2. In the community, there are legitimate contradictions between the interests of individuals

3. The strength of an individual or group should not lead to their imposition on others

4. The parties involved must interact with one another to complete each other's information and try to understand each other's perspective and reduce the controversy

5. No individual or group should be dropped in the process of reaching an agreement

\section{Participatory planning spectrum}

The study provides a range of participatory planning elements which includes

\section{Engagement}

Entering the deliberative process with others, listening actively to their opinions, information and views when there is clearly a lack of power between the parties; contrary to mediation and negotiation, engagement (absorbing and engaging people to the participation process) can also be done without a disagreement to resolve. Engagement is a means to identify and clarify disagreements by listening to different interests (Hersperger et al., 2018).

Engagement is usually, but not necessarily, initiated by planners. It is sensitive to the diversity of needs, the importance of paying attention to the differences and where agreements are made.

\section{Negotiation}

The process of reaching an agreement is through the exchange of opinions and information, bargaining and compromise between two or more parties that have some common interests and some different interest 
(Suebvises, 2018). Negotiation can also be a part of the mediation process, but it can also take place outsidethe formal domain of mediation and without the assistance of neutral people. Negotiation takes place usually between stakeholders or planners and other parties.

\section{Pre-Mediation}

It is a process in which the planner acts as a mediator by listening to the stakeholders, helping to identify potential conflicts in order to resolve disputes and reach an agreement to formulate a program.

Pre-mediation is used when potential conflicts exist. Representatives of the planning authorities act as neutral (and or informal) mediators between two or more parties to the planning process.

\section{Mediation}

It is the process of resolving disputes voluntarily, unwillingly and without bias, by neutral people, which help the parties to negotiate during the negotiation process.

Mediation is used in cases when the conflicts can't be solved by the planners or other parties and are performed by a third party.

The above items are not considered as stage steps. There may be a linear arrangement of commitment to mediation, but this is not obligatory.

\section{TheDifference of Participatory Planning with Similar Concepts}

It has been emphasized in the study to distinguish between public participation and public consultation with participatory planning. The definition of other concepts in this study is as follows.

Public Participation is a process driven by planners. Planners try to design a plan tailored to the needs and consistent with national politics through the projection and estimation of the general public needs and their integration. Participation is designed and implemented by planners. Public participation involves certain stages for understanding topics and planning for them. In this way, the flow of information is mainly from the planners towards the people.

\section{Looking at the Participation}

Different types of participation are different in terms of participation as a goal or device. If participation is taken as a goal on its own, we will be closer to genuine participation.Insuperficialparticipation, it is considered as an appropriate mean of facilitating the implementation of the project.

\section{Citizens' Pol}

In this point of view, the different levels of participation are also different. The more serious and comprehensive the citizens' polls are; we will get closer to genuine participation.

\section{Right to Protest the Plan}

The right to protest the plan, along with the mechanisms for putting these objections into the plan -in a way to serve the public interest- is an appropriate means to measure the real extent of the participation of the people. In a genuine participation plan, all stakeholders have the right to protest the plan and present alternative theories and suggestions.

\section{Classification of Theories According to theConditions of Iran}

According to the above criteria, participation theories can be divided into three categories according to the conditions of Iran: (1) Slogan participation (2) limited participation (3) genuine participation.

\section{Slogan Participation}

In fact, it is not participation, but a claim to have participation. The main intention is not to provide the interests of the people, but to provide the interests of planning authorities. The main reason for participation is gaining legitimacy for the plan and reduction of people's resistance and, consequently, ease of implementation of the plan. People don't have any part in decision-making and policy-making. The fewest possible information about the plan is given to the publicand the published information only contains the strengths and effects of the plan and does not address the negative effects of the planand essentially, the existence of any negative effects in the plan is denied.

The intellectual and philosophical backing for this concept is absoluteness. In this concept, people are not counted. The scope for the participation of people is very limited and in the best way, it is only limited to financing the project. The only participatory aspect of the slogan participation is the participation of citizens in the probable future profitability of the project, only if they can participate in the financing of the plan.

Although slogan participation is not really participation, it is pretending to be formal and passive participation, but the slogan of participation in a community is a step forward, because.

First, participation is expressed in terms of expression and opinionand it is better than the lack of participation even in speaking.

Secondly, when participation is accepted in the form of a slogan, it is accepted as a social value tooand in the event of further attention, this value can be internalized and provide the basis for the limited, genuine participation.

Therefore, the slogan participation should be viewed as an introduction to the genuine participation and it 
does not generally reject it. It is essential to go through the stage of slogan participation in developing societies, but it should not be stopped there.

\section{Limited Participation}

The main intention is to provide the interests of the people so far as to not conflict with the interests of the state and the planning authorities. People have no share in decision making and targeting. People have the right to comment and protest, but they cannot monitor the implementation of their opinions and follow their demands.

Participation is considered as a tool for improving the quality of plans. The flow of information is mainly from the bottom to up, that is, the information is transmitted by the people to the planner. The scope of participation is limited to financing in the projects and considering people's view in some planning cases. The intellectual and philosophical backing of this kind of participation is functional and technical views.

\section{Genuine Participation}

The main intention is to maximize the interests of the public and satisfy them. The cost of this is provided by the government or sponsoring organization. Citizens participate in decision making and targeting. In addition, citizens have the right to comment, they have the right to protest and oppose the plan and have the right to monitor the implementation of their demands.

Participation, besides being an instrument for improving the quality of the projects, is also considered as a goal and promotes the intellectual, social and civilian growth of citizens. The flow of information is two-way and very active and planning authorities and people share their information. The intellectual backing of this kind of participation is the views of liberal democracy and direct participation (not merely the participation of representatives).

\section{Conclusion}

According to the studies in this article, urban planning has not changed muchand urban plans are being prepared according to the same style and methodology; despite the wide-ranging developments in the political, economic, social and technological fields of the world and increase in the level of knowledge and awareness of the people and the increasing need to public participation in the world. Citizens are not consulted and the citizen has the right to protest the plansand in fact, the slogan participation versus genuine participation, which is the most complete form of participation, is ruled out in contemporary societies. With these interpretations, planners have to prepare themselves to use the ideas of the people in their plans, because of the prospect of the future of planning involves an act openly embracing various social and political values to be discussed and studied. Applying this position means to deny the plans that the planner is a single subject and technician. In other words, we need to change our planning method, these changes do not happen without changing planners' mentality and defining a new role for them to achieve a desirable society.

\section{Author's Contributions}

All authors equally contributed in this work.

\section{Ethics}

The present Study and ethical aspect were approved by the Isfahan University of the Technology. The present study was approved by the Isfahan University of Technology.

\section{References}

Bice, A. A. (2018). Cognitive dissonance and pediatric procedural pain management: A concept clarification. Pain Management Nursing, 19 (3), 230237. https://doi.org/10.1016/j.pmn.2017.07.005

Davidoff, P., 2012. Advocacy and pluralism in planning. Abadname Journal, 3, 60-78. https://doi.org/10.1080/01944369408975562

Deitz, M., Notley, T., Catanzaro, M., Third, A., \& Sandbach, K. (2018). Emotion mapping: Using participatory media to support young people's participation in urban design. Emotion, Space and Society, 28, 9-17. https://doi.org/10.1016/j.emospa.2018.05.009

Forester, J. (2013). On the theory and practice of critical pragmatism: Deliberative practice and creative negotiations. Planning Theory, 12(1), 5-22. https://doi.org/10.1177/1473095212448750

Hersperger, A. M., Oliveira, E., Pagliarin, S., Palka, G., Verburg, P., Bolliger, J., \& Grădinaru, S. (2018). Urban land-use change: The role of strategic spatial planning. Global Environmental Change, 51, 32-42. https://doi.org/10.1016/j.gloenvcha.2018.05.001

Justin Hui, A., 1998. Citizen participation in the design and development of urban areas. Journal Architecture Urban Development.

Kim, J. Y. (2017). Interim third-party selection in bargaining. Games and Economic Behavior, 102, 645-665. https://doi.org/10.1016/j.geb.2017.02.013

Kolonin, A. (2018). Architecture of Internet Agent with Social Awareness. Procedia Computer Science, 123, 240-245.

https://doi.org/10.1016/j.procs.2018.01.037 
Kovács, E., Kelemen, E., Kiss, G., Kalóczkai, Á., Fabók, V., Mihók, B., ... \& Molnár, D. (2017). Evaluation of participatory planning: Lessons from Hungarian Natura 2000 management planning processes. Journal of Environmental Management, 204, 540-550. https://doi.org/10.1016/j.jenvman.2017.09.028

Rall, E., R. Hansen and S. Pauleit, 2018. The added value of Public Participation GIS (PPGIS) for urban green infrastructure planning. Urban Forestry and Urban Greening, 40, 264-274. https://doi.org/10.1016/j.ufug.2018.06.016
Suebvises, P. (2018). Social capital, citizen participation in public administration and public sector performance in Thailand. World Development, 109, 236-248. https://doi.org/10.1016/j.worlddev.2018.05.007 